\title{
NOTAS SOBRE PARATOPIA CRIADORA: O CASO DE JANE AUSTEN PARA ALEM DE SUA FORTUNA CRÍTICA
}

\section{Notes about creative paratopy: the Jane Austen case beyond its critical fortune}

\author{
Luciana Salazar SALGADO ${ }^{71}$ \\ Amanda Aparecida CHIEREGATTI ${ }^{72}$
}

Resumo | Com base no quadro teórico da Análise do Discurso de tradição francesa, particularmente em trabalhos recentes de Dominique Maingueneau (2006, 2008) sobre o que refere por discurso literário, focalizamos neste artigo um estudo de caso: o funcionamento da autoria de Jane Austen. Mobilizamos, para tanto, noções constitutivas da paratopia criadora, a saber, escritor, inscritor e pessoa. E, então, consideramos, além da produção dos textos autorais, material biográfico e variados estudos que circulam sobre a romancista, que tem fãs no mundo todo, entre os quais muitos se organizam em grupos de estudos e de celebração. Assim, tendo em vista o contexto social da Inglaterra na passagem do século XVIII para o XIX, quando é publicada a obra de Austen, procuramos compreender os elementos constitutivos da consagração da autora, que publicou sob pseudônimo e é aclamada hoje pela construção do que podemos chamar de uma "combativa identidade feminina".

Palavras-chave | Paratopia criadora. Discurso constituinte. Ritos genéticos. Mediação editorial.

\begin{abstract}
Based on the theoretical framework of Discourse Analysis, particularly on studies about the literary discourse by Dominique Maingueneau (2006, 2012), we focus in this article Jane Austen's authorship case, taking into account some biographical material and studies about the novelist, who has fans all over the world, among which many are organized in study groups. Considering the social context of England from the $18^{\text {th }}$ to the $19^{\text {th }}$-century, when the work of Austen appeared, we tried to understand the consecration of this author, who published under a pseudonym first and is hailed nowadays by what we could refer as a "combative female identity". We mobilize then three notions to explain this creative paratopy: the writer, the inscriptor and the person.
\end{abstract}

Keywords | Creative paratopy. Constitutive discourse. Genetic rites. Publishing mediation.

71 Salgado. UFSCar. Endereço eletrônico: lucianasalazarsalgado@gmail.com. ORCID ID: https://orcid. org/0000-0002-1052-0726

72 Chieregatti. UFSCar. Endereço eletrônico: amandachieregatti@yahoo.com.br. ORCID ID: https://orcid. org/0000-0001-5958-9268 
- Notas sobre paratopia criadora: o caso de Jane Austen para além de sua fortuna crítica

\section{O literário como discurso}

Ainda que em alguns círculos se considere com tranquilidade que o material referido por literário pode ser apreendido na ordem do discurso, o que supõe levar em conta as especificidades que o diferenciam, por exemplo, dos regimes discursivos midiático, político, religioso, entre outros, parece evidente que a legitimação da pesquisa sobre o discurso literário demanda, ainda, estudos que contribuam para o desenvolvimento de aparatos teórico-metodológicos esclarecedores de categorias difusas como autoria e editoria, por exemplo, e que, com isso, participem de uma reflexão fundamental na contemporaneidade: as inscrições materiais do literário.

Neste artigo, para indicar brevemente a linha de força que dá sustentação ao estudo que ora apresentamos, convocamos os termos de um trabalho recente de Roger Chartier (2012, p. 81), que opera no cruzamento da sociologia dos textos com a história da leitura, no qual aponta para uma "[...] aliança entre as disciplinas de interpretação e os saberes sobre os objetos", aproximando sua reflexão sobre autoria de uma semiologia material:

[...] uma única e mesma perspectiva intelectual deve reunir, mesmo se cada um de nós tem competências mais específicas em um domínio ou outro, a análise dos textos em sua estrutura, sua significação, sua organização retórica, demonstrativa, persuasiva; as análises das formas nas quais eles se inscrevem, quer sejam essas formas a voz de um leitor ou de um orador, quer sejam a série de objetos impressos nos quais eles foram desenvolvidos; e a análise da construção de seu sentido possível por diferentes comunidades de leitores ou por diferentes leitores singulares ao longo do tempo. (CHARTIER, 2012, p. 81).

Essa perspectiva, estribada na condição dialógica da palavra, como se sabe, no caso dos textos postos em circulação pública como objetos editoriais, pode ser retomada na formulação cirúrgica de Roger Stoddard: "Os livros não são de modo nenhum escritos. São manufaturados por escribas e outros artesãos, por mecânicos e outros engenheiros, por impressoras e outras máquinas" (STODDARD apud BENTON; GUTJAHR, 2001, p. 141, tradução nossa). O que tem norteado pesquisas em diversos campos de saber, que entendem, com isso, que:

Certamente seria útil examinar como o autor se tornou individualizado numa cultura como a nossa [ocidental], que status Ihe foi conferido, em que momento os estudos de autenticidade e atribuição de autoria começam, em que tipo de sistema de valores a figura de autor foi envolvida, em que ponto começamos a recontar as biografias dos autores em vez das histórias de heróis e como se instituiu essa categoria fundamental da "crítica do homem e seu trabalho". (WOODMANSEE; JASZI, 1994, p. 30, tradução nossa). 
Diante desse tipo de questão é que temos abordado as materialidades de inscrição do discurso literário e, valendo-nos de propostas teóricas de Dominique Maingueneau, temos conduzido estudos de caso com base num conjunto de noções correlatas, que se pode apresentar sumariamente assim: trata-se de estudar um discurso constituinte, cujas condições de produção incluem ritos genéticos, conjuradores das condições de recepção, que são, elas também, constitutivas da paratopia criadora.

Assim, o discurso literário (ligado à Arte), como o discurso filosófico (ligado à Razão) ou como o discurso religioso (ligado a Deus), é ao mesmo tempo autoconstituinte e heteroconstituinte, pois, tematizando a própria constituição, faz as vezes de matériaprima irredutível de outros regimes discursivos; os discursos constituintes põem-se como ligados sem qualquer mediação a uma fonte suprema, supra-humana, legitimados per se. Por isso, os ritos genéticos que os organizam são cruciais: definem os objetos culturais que os constituem, quem os produz, como circulam.

Esses ritos fazem parte das condições de produção que caracterizam um autor num dado campo, um conjunto de autores, um conjunto de textos e a própria possibilidade de um campo, levando em conta sempre que as condições de circulação dos textos autorais estão projetadas nesses ritos, isto é, em boa medida deriva deles, embora não sejam desdobramento linear de um projeto inteiramente controlado.

Nos estudos conduzidos por essa pauta, vê-se que os campos definidos por discursos constituintes frequentemente se puseram como apartados de qualquer ideia de mercado (eventualmente, algo por demais "mundano"), embora tenham sempre estabelecido ambientes de troca que lhe viabilizaram a existência (que efetivamente constitui o "mundo humano"). Um ponto fundamental nesses estudos reside no fato de essas práticas de produção e de consumo conviverem com uma figura de autor "genial", cuja "originalidade" é a razão pela qual a ele deve ser atribuída a celebridade de um criador plenamente autônomo - mas só se constitui um autor com a dispersão de escritos e a constituição de um público que lhes dá sentido. Para tratar disso, Maingueneau (2006) organiza um modelo teórico que permite examinar a autoria como lugar discursivo em permanente construção: como paratopia criadora. É nessa noção que gostaríamos de nos deter.

Assumimos, para tanto, que se trata de desdobrar reflexões sobre o ato de criar, nos termos da célebre formulação de Nietzsche para esse "lugar paralelo" sobre o qual se erige a possibilidade do trabalho de criação: "[...] um Homero não teria criado um Aquiles, um Goethe não teria criado um Fausto, se Homero tivesse sido Aquiles, e Goethe um Fausto" (NIETZSCHE, 1998, p. 91). Nessa perspectiva, Maingueneau aborda como parte fundamental desse trabalho os ritos genéticos, entendendo que um escritor é de fato obrigado a inventar seus ritos na medida da sua necessidade, para estabelecer uma espécie de enlaçamento: "[...] é preciso já ter encontrado os ritos genéticos pertinentes 
- Notas sobre paratopia criadora: o caso de Jane Austen para além de sua fortuna crítica

para elaborar as obras, mas é o êxito das obras realizadas que consagra a pertinência desses ritos" (MAINGUENEAU, 2006, p. 157). E o modo como são cultivados e explicitados nas obras (ou não) tem configurações históricas; a espontaneidade romântica ou o árduo labor parnasiano, por exemplo, são ambos efeitos de ritos genéticos que se tematizam com formas próprias a cada um desses efeitos. Nesses termos é que podemos falar em criação na ordem do discurso, isto é, numa gênese que tem a ver com o trabalho sobre os sentidos produzíveis nos textos, que não são autotélicos nem mensagem de uma instância supra-humana. Desse modo, os ritos genéticos são gestos conjuradores, isto é, constroem um lugar social que, espera-se, deve legitimar essa construção:

Esses ritos constituem, na verdade, o único aspecto da criação que ele [escritor autor] pode controlar, a única maneira de conjurar o espectro do fracasso. Em matéria de criação, o êxito é profundamente incerto: como se assegurar de que se fez uma obra de valor quando nem mesmo a aprovação do público imediato é um critério seguro? Não resta ao autor senão multiplicar os gestos conjuradores, mostrar a si mesmo e ao público os sinais de sua legitimidade. (MAINGUENEAU, 2006, p. 156).

Dessa consideração decorre que a autoria seja examinada como um lugar de dinâmicas em tessitura, não como papel social ou lugar de fala ou efeito de sentido de uma dada textualização, mas, sim, como implicação entre tais instâncias. Implicação, vale dizer, sem simetrias ou homologias previamente dadas entre elas; implicação a partir da qual se produzem inescapavelmente outras - a conhecer, se se pretende estudar uma dada produção autoral.

\section{O caso Jane Austen}

Na última década, passados quase dois séculos desde a morte da escritora inglesa Jane Austen, sua obra tem sido muito comentada e ganhou uma vasta quantidade de adaptações como filmes, seriados, incontáveis releituras, e embora as famosas obras de Austen tenham ganhado adaptações desde a década de 1930, é como se seus escritos houvessem sido redescobertos recentemente.

Atualmente, além de adaptações cinematográficas e televisivas, multiplicaram-se também documentários e ficções baseadas na vida da escritora, e a circulação do nome Jane Austen tem uma abrangência cada vez maior, verificável na realização de festivais anuais em homenagem à autora e no desenvolvimento de videogames que contam com a presença de seus personagens mais conhecidos. Estes são apenas alguns exemplos do modo como Jane Austen e sua obra circulam hoje para além de seus escritos. 
Da perspectiva discursiva com que delimitamos o conjunto de dados apresentados a seguir, parece possível dizer que há indícios de que as mudanças históricas ocorridas nos dois séculos transcorridos desde a produção de seus romances é que nos fazem lêlos como uma crítica feminista à sociedade patriarcal. Pareceu-nos interessante, então, investigar o que faz tão "atual" a autora de romances: quatro publicados em vida, sob pseudônimo, e três publicados após sua morte, dois romances prefaciados pelo irmão Henry Austen, e um romance epistolar intitulado Lady Susan que, apesar de ter sido vendido pela autora muito antes de ter um de seus romances editados, só veio a público meio século após a morte da escritora, já em 1871.

A gestão editorial desses textos, articulada a partir de traços biográficos, como o fato de Austen ser uma mulher solteira numa sociedade patriarcal em que as mulheres vivem necessariamente às expensas dos homens (pai, marido, irmão ou parente próximo, conforme as hierarquias familiares) e a questões ditas "de estilo", como o manejo licencioso do discurso indireto livre, trazendo sistematicamente à tona pensamentos "indizíveis", erigiu uma imagem de autora frequentemente retomada como feminista (CHIEREGATTI, 2014).

Com base nisso, podemos depreender que a autoria se delineia em um enlaçamento de registros que forjam uma unidade autoral, que só existe "mediante uma atividade de criação e de enunciação" (MAINGUENEAU, 2006, p. 109). Essa paratopia criadora situa num "impossível lugar" as relações entre o escritor e a sociedade, o escritor e sua obra, a obra e a sociedade, pois, "[...] para produzir enunciados reconhecidos como literários, é preciso apresentar-se como escritor, definir-se com relação às representações e aos comportamentos associados a essa condição" (MAINGUENEAU, 2006, p. 89). Esse topos faz-se, assim, de uma negociação entre um lugar e um não-lugar, e sua existência só é possível se integrada a um processo criador:

A paratopia envolve o processo criador, que também a envolve: fazer uma obra é, num só movimento, produzi-la e construir por esse mesmo ato as condições que permitem produzir essa obra. Logo, não há "situação" paratópica exterior a um processo de criação: dada e elaborada, estruturante e estruturada, a paratopia é simultaneamente aquilo de que se precisa ficar livre por meio da criação e aquilo que a criação aprofunda; é a um só tempo aquilo que cria a possibilidade de acesso a um lugar e aquilo que proíbe todo pertencimento. (MAINGUENEAU, 2006, p. 109).

A partir disso, as instâncias que Maingueneau entende como constitutivas da autoria são: i) pessoa, o ser histórico, membro de uma família, de um círculo social, que se reúne ou não com amigos, estudou nesta ou naquela instituição, não estudou...; ii) escritor, que se refere à circulação da obra, a seu modo de difusão, que "[...] vai de mãos dadas com o modo de consumo do discurso, isto é, com o que se 'faz' dos textos, 
- Notas sobre paratopia criadora: o caso de Jane Austen para além de sua fortuna crítica

como eles são lidos, manipulados" (MAINGUENEAU, 2008, p. 134), por quem são (se são) resenhados, comentados, retomados em entrevistas, se aparecem (e como aparecem) em feiras, prêmios...; iii) inscritor, instância que se produz fundamentalmente com os ritos genéticos, isto é, com "[...] o conjunto de atos realizados por um sujeito em vista de produzir um enunciado" (MAINGUENEAU, 2008, p. 132), ou seja, tudo o que o autor, enquanto escriba, mobiliza na constituição de sua obra, desde os recursos retóricos ao fato de o texto ser ou não assinado, ou circular sob pseudônimo, bem como todos os ritos editoriais que produzem sua condição material de existência.

Essas instâncias funcionam em interdependência, e só na sua conexão tripla é que definem a autoria: trata-se de um nó borromeano. Em outros termos, trata-se de entender que "[...] os escritores produzem obras, mas escritores e obras são, num dado sentido, produzidos eles mesmos por todo um complexo institucional de práticas" (MAINGUENEAU, 2006, p. 53).

No caso de Jane Austen, para prosseguir nas pesquisas indicadas pela pergunta sobre a "contemporaneidade" dessa autora, ou seja, sobre a constituição de seu "impossível lugar", consideramos o imbricamento de dados biográficos, as várias edições e transmidiações de seus textos e informações referentes aos próprios processos de publicação das obras e de objetos derivados, e também a tessitura de seus romances Razão e Sensibilidade (1811), Orgulho e Preconceito (1813) e Persuasão (1818), que são os mais retomados nessa "onda atualizadora".

\section{Instância pessoa - uma vida, um ícone}

A instância pessoa do referido nó borromeano se assenta nos dados biográficos postos em circulação em um espaço associado, que se cria em torno da circulação dos textos literários. No caso de Austen, remete a um modus vivendi típico do contexto inglês da passagem do século XVIII ao XIX: filha de um reverendo, era de uma família numerosa, cresceu dispondo de uma modesta biblioteca particular e viveu às expensas dos irmãos após a morte do pai. Importante frisar que não se trata, aqui, de buscar na biografia a explicação da obra ou na obra a explicação da vida, mas de levar em consideração, de uma perspectiva discursiva, que a delimitação de um lugar de fala institucionalizado pressupõe dados da história de uma trajetória que são mobilizados nessa institucionalização; o autor que publica (uma condição institucionalizada conforme a conjuntura de um dado período) toma a palavra em um projeto de criação que visa à circulação pública, visa a algum tipo de pertencimento a uma dada organização social, inscreve-se, portanto, numa dinâmica interlocutiva a partir de condições dadas, manobrando nas injunções delimitadoras dessa autoria. A instância pessoa, nesse modelo teórico, tem a ver, então, com os indícios de que um sujeito histórico manobra nessas injunções. 
No caso de Austen, os temas de que trata, do modo como os trata, remetem à conjuntura histórica em que efetivamente trabalhou sua escrita, o que enfatiza, nesta constituição autoral, o jogo entre pessoa e escritor. Possivelmente isso explique a multiplicação de objetos paraeditoriais, que chegam a alguns itens bastante indicativos dessa superposição de instâncias, como, por exemplo, a action figure da autora - que não é, a princípio, uma personagem, como se supõe nesse tipo de "boneco". Entretanto, se se considerar que pouco se sabe efetivamente sobre Austen, na medida em que é bastante mediada a compilação póstuma de seus dados biográficos - seu epistolário, por exemplo, reúne cartas selecionadas por familiares que queimaram as outras -, caberá considerar a "personagem" que se produziu a partir daí. Sobre seu rosto, de fato, pouco registro há, no entanto, há até mesmo formas de bolo com um perfil que acabou consagrado como sendo o da autora. ${ }^{73}$

\section{Instância inscritor - as mãos que conduzem a pena}

O termo "inscrição" é mobilizado, neste modelo teórico, como o modo de escrever sobre o que se escreve. Trata-se dos ritos genéticos fundamentalmente e, mais além, dos ritos editoriais, se considerarmos os processos que, entre os originais do autor e o livro nas mãos de um leitor são diversos, ultrapassando em muito os condicionamentos definidores da instância pessoa.

Assim, o fato de Austen ter publicado sob o pseudônimo "By a Lady" é uma informação bastante importante: é uma definição inscricional, que condiciona a gestão da obra no espaço público (a instância escritor) e o faz conforme injunções produtoras de certos ritos pessoais (a instância pessoa). Austen se inscrevia como autora em uma sociedade que olhava com forte preconceito o fato de uma mulher dedicar-se à literatura em vez de ocupar-se de seu casamento. Para circular, era preciso, de algum modo, medir palavras. Fosse para evitar julgamentos ou pela simples decisão de não expor a própria obra a uma desvalorização, o fato é que seu pseudônimo não deixava de apontar para uma mulher como autora dos textos. Sobre isso, consideremos que

[...] refletir sobre a emergência de obras é considerar o espaço que lhes dá sentido, o ambiente em que se constroem os posicionamentos: doutrinas, escolas, movimentos... Trata-se da construção de uma identidade enunciativa que é tanto "tomada de posição" como recorte de um território cujas fronteiras devem ser incessantemente redefinidas. (MAINGUENEAU, 2006, p. 151).

73 Sobre a profusão de objetos paraeditoriais que avolumam o espaço associado, atribuindo valor ao espaço canônico, isto é, aos textos autorais de Austen, ver Chieregatti (2014). 
- Notas sobre paratopia criadora: o caso de Jane Austen para além de sua fortuna crítica

Em uma primeira abordagem do conjunto de títulos que compõem a obra literária de Austen, logo notamos que seus textos são sempre protagonizados por mulheres que norteiam a leitura, seja por sua presença constante ou por suas falas em pontos nevrálgicos das narrativas. Vale dizer que, apesar de seus textos serem muito comentados a partir de suas protagonistas, frequentemente avessas ao que é imposto pela sociedade inglesa do período, também apresentam o universo feminino por meio de diversas personagens que encarnam a dinâmica induzida por uma aristocracia rural de forte viés patrimonial, aliada, aos poucos, a uma burguesia urbana afeita a títulos nobiliárquicos. A seguir, alguns excertos das várias representações da mulher no texto Razão e Sensibilidade (1811), o primeiro publicado ${ }^{74}$.

Comecemos pela personagem mais estereotípica presente nessa narrativa, a Sra. Jennings, viúva que tem só duas filhas (coisa incomum diante das grandes proles características do período), e estas, estando já casadas, não ocupam mais a mãe, que, ociosa, dedica-se a arranjar casamentos entre seus conhecidos. A personagem é descrita da perspectiva de Marianne, uma das principais personagens da trama:

Numa só coisa, porém, ela era constante ao tratar deste ponto: em evitar, quanto possível, a presença da sra. Jennings, e no obstinado silêncio ao ser obrigada a tolerá-la. Seu coração se recusava a crer que a sra. Jennings tivesse qualquer compaixão pela sua dor. "Não, não, não, não pode ser", exclamou ela, "ela não pode sentir. Sua gentileza não é comiseração; sua bonomia não é ternura. Tudo o que ela quer é matéria para fofoca, só gosta de mim agora porque posso fornecer-lhe o que quer". (AUSTEN, 2012b, p. 248).

Decerto a construção da personagem é uma crítica a certo papel social desempenhado por mulheres oitocentistas: uma vez que as moças eram educadas única e exclusivamente para o casamento, seria natural que o único objetivo de uma mãe fosse casar as filhas e, tendo feito isso, sua existência só teria sentido se continuasse fazendo por outras moças. Casar-se e casar mais moças é função primordial das mulheres.

Ainda em Razão e Sensibilidade (1811), há também personagens como lady Middleton, uma figura apática que só se ocupa em preparar festas e jantares, e cuidar dos quatro filhos que também são o assunto de todas as conversas. Ou Fanny, a sra. John

\footnotetext{
74 Não discorreremos aqui sobre um aspecto importante da dimensão inscricional, sobretudo no caso de textos literários: a tradução. Sabidamente, há uma farta produção teórica e analítica a esse respeito, que atesta a grandeza da problemática. Nesta ocasião, considerando-a, optamos por pôr em relevo textos traduzidos pela editora Martin Claret, cuja circulação, se põe problemas para os afeitos aos livros e processos editoriais (cf. http://www.janeausten.com.br/uma-otima-noticia-sobre-plagios/e http://naogostodeplagio.blogspot. com.br/2009/03/liz-bennet-kidnapped.html), é fonte de edições das que mais ampliam a distribuição dos textos de Austen, alcançando com sua logística de distribuição e seu preço, além da estratégia de títulos associados, um público editorialmente desavisado. É, portanto, com essas feições que a maior parte dos leitores de Austen em português brasileiro se confronta.
} 
Dashwood, cunhada das irmãs Dashwood, uma mulher mesquinha e egoísta que só pensa no próprio bem e nos próprios bens; para ela não há absurdo maior do que o marido propor ajudar financeiramente a madrasta viúva e as irmãs. Ao descrever o encontro dessas duas personagens peculiares, Austen (2012b, p. 281) não poupa acidez: “[...] havia uma frieza egoísta em ambas, que as atraiu mutuamente".

Já em Orgulho e Preconceito (1813), o destaque está no fato de a protagonista Elizabeth Bennet ter recusado não uma, mas duas propostas de casamento em uma época em que o matrimônio era a única maneira de uma jovem sem posses garantir uma vida confortável para si e para a família, e também no comportamento pouco comedido de sua irmã caçula, Lydia Bennet, que, aos quinze anos, não hesita em flertar com praticamente todos os oficiais do regimento presente em Meryton.

Já no primeiro parágrafo da trama, com recurso à recorrente ironia, a autora apresenta a situação das famílias que tinham jovens solteiras nessa conjuntura:

É uma verdade universalmente conhecida que um homem solteiro e muito rico precisa de uma esposa. Por menos conhecidos que sejam os sentimentos ou as ideias de tal homem ao entrar pela primeira vez em certo lugarejo, tal verdade está tão bem arraigada na mente das famílias que o rodeiam, que ele vem a ser considerado propriedade legítima de uma ou outra de suas filhas. (AUSTEN, 2012a, p. 9).

Não é um homem solteiro e rico que precisa de uma esposa, como fica claro no desenrolar do romance, mas, sim, a mulher que precisa desesperadamente do matrimônio.

Em determinada passagem de Persuasão (1818), por sua vez, em um diálogo com o capitão Harville, a protagonista Anne Elliot defende que não faz parte da natureza feminina esquecer um amor facilmente, e critica o condicionamento social da mulher:

- [...] Certamente não os esquecemos tão rapidamente como vocês nos esquecem. Talvez seja mais nosso destino do que nosso mérito. Não podemos evitá-lo. Vivemos em casa, caladas, trancadas, vítimas de nossos próprios sentimentos. Vocês são forçados à ação. Sempre têm uma profissão, objetivos, afazeres de um tipo ou de outro que os trazem imediatamente de volta ao mundo, e a ocupação e a mudança contínuos logo desbotam as impressões. (AUSTEN, 2012c, p. 279-280).

Pouco tempo depois, ainda dialogando com o capitão, Anne ressalta as diferenças entre a educação masculina e a feminina: 
- Notas sobre paratopia criadora: o caso de Jane Austen para além de sua fortuna crítica

- [...] Os homens tiveram todas as vantagens contra nós, ao contarem sua própria história. Tiveram sempre uma educação muito superior, a pena estava em suas mãos. Não admito que os livros provem coisa nenhuma.

- Mas como provaremos alguma coisa?

- Jamais provaremos nada. Não é de se esperar que se possa provar alguma coisa numa questão como essa. É uma diferença de opinião que não admite prova. Todos nós, provavelmente, começamos com certa parcialidade a favor de nosso próprio sexo, e nessa parcialidade fundamos todas as circunstâncias favoráveis a ela que aconteceram em nossa própria esfera. Muitas dessas circunstâncias (talvez justamente aquelas que mais nos impressionam) podem ser exatamente aquelas que não podem ser reveladas sem trair um segundo ou de alguma forma dizer o que não se deveria dizer. (AUSTEN, 2012c, p. 281-282).

Nesse excerto, há indícios de que Jane Austen pudesse estar tratando de sua própria condição de escritora - o fato de escrever em um período em que a literatura era predominantemente feita por homens e o fato de ter recebido instrução em casa, enquanto os irmãos frequentaram escolas, com as decorrências previsíveis, como ser editada por mediações de parentes homens, sem que pudesse receber os devidos créditos ou mesmo atuar sobre os processos de gestão da sua obra. Cabe pensar, mais além, em todos os processos editoriais pelos quais esses textos passaram e passam, suas tantas reedições, as traduções que se sucederam em diversas línguas já sem o controle dos familiares, sendo algumas delas bastante descuidadas: a recepção dos textos certamente é afetada por essas etapas que são tanto de produção quanto de mediação (Cf. sobre recepção desta perspectiva discursiva SALGADO, 2016).

\section{Instância escritor - uma escritora feita de leituras}

Consideremos, para entender a instância escritor, que a gestão pública da obra tem a ver com os ritos genéticos e com toda a trajetória do ser histórico que os engendra, assim como com os trabalhos editoriais que definem a materialidade de difusão dos escritos, mas ultrapassa cada uma dessas medidas. No caso da paratopia criadora em Jane Austen, verifica-se que está muito fortemente relacionada ao que se fala da autora e de suas obras, às formas de retomada e transformação de seus textos, personagens e episódios vividos. Diversas biografias foram escritas, inclusive por familiares, filtro relevante que amalgama aspectos da instância pessoa à instância escritor: o irmão Henry, muito dedicado à publicação dos textos de Jane, publicou em 1833 uma breve biografia da irmã intitulada Memoir of Miss Austen, além do prefácio em que revelou a identidade da já aclamada autora que assinava "By a Lady"; em 1870, o sobrinho J. E. Austen-Leigh publicou A Memoir of Jane Austen, seguido por suas irmãs Anna Austen (posteriormente Anna Lefroy) e Caroline Austen, que publicaram, respectivamente, Recollections of Aunt 
Jane (1864) e My Aunt Jane Austen (1867). Essas vozes dão feições a uma Austen que, sendo uma familiar, ao ser construída por eles também os constrói; de fato, essas vozes dão feições a uma linhagem.

Em uma pesquisa ligeira em qualquer buscador na internet, é possível encontrar uma lista bastante extensa de ocorrências que atestam a intensidade da circulação contemporânea da obra de Austen, ligada a diferentes retomadas dessas biografias. Assim, consideramos que

O escritor é alguém que não tem um lugar/uma razão de ser (nos dois sentidos da locução) e que deve construir o território por meio dessa falha. [...] alguém cuja enunciação se constitui através da própria impossibilidade de atribuir a si um verdadeiro lugar, que alimenta sua criação do caráter radicalmente problemático de seu próprio pertencimento ao campo literário e à sociedade. (MAINGUENEAU, 2006, p. 108).

Consideremos, então, que a obra de Austen se produz na mesma mão que a autoria de Austen se instaura, não precisamente no período assinado por "By a Lady", mas, com a memória dessa circulação, passando pela solene revelação feita pelo irmão em prefácio à publicação póstuma, chegando a ser inspiração para diversos escritores que se baseiam nas histórias criadas pela autora para criar as suas próprias (o que abre para uma reflexão sobre a datação das fanfics, ficções produzidas por fãs sob rigorosos ritos, que têm sido entendidas como típicas da contemporaneidade). Além do fato de todos os romances de Austen terem recebido adaptações cinematográficas ou televisivas, o fascínio pela obra da autora inglesa é tanto que sua vida também é abordada em diversos filmes ficcionais, documentários e livros de diversos regimes discursivos. Dado que nos parece muito relevante na medida que mostra como um autor (o que se diz sobre sua vida, seu modo de trabalho etc.) pode ser construído documentalmente ou romanceadamente, e todas as construções se entrelaçam constituindo o imaginário social sobre tal autor e sua obra; e também mostra como as instâncias se entrelaçam: a produção de dizeres sobre a vida de Austen, ao mesmo tempo que institui uma circulação social de sua autoria (isto é, de sua relação com um conjunto de textos conhecido socialmente como obra), recorre a aspectos biográficos, a traços da existência histórica para compor esse gerenciamento.

Em todo caso, é difícil afirmar com exatidão quando esse fascínio por Jane Austen começou, mas podemos observar que a maioria das releituras foram publicadas principalmente a partir de 2007, ano em que foram lançados dois filmes: Becoming Jane (dirigido por Julian Jarrold), no Brasil Amor e Inocência, que retrata a vida de Austen antes de seu romance com Tom Lefroy, e The Jane Austen Book Club (escrito e dirigido por Robin Swicord), no Brasil O Clube de Leitura de Jane Austen, que é baseado no livro homônimo de Karen Joy Foeler (2004) e focaliza um clube formado especificamente para discutir os 
- Notas sobre paratopia criadora: o caso de Jane Austen para além de sua fortuna crítica

romances escritos por Jane Austen: os membros se encontram para tratar de experiências de vida que se assemelham aos temas dos livros.

Essa circulação massiva que não se limita à publicação de livros gerou, nas duas últimas décadas, pelo menos 27 adaptações de suas obras, dois longa-metragens e três documentários a respeito da vida da autora. É possível, ainda, encontrar blogs e sites em diversos países, além de grupos de estudos e clubes de leitura não acadêmicos, embora a autora e sua obra estejam bastante presentes em trabalhos como monografias, dissertações e teses. Em 2012, ocorreu um evento inédito no meio acadêmico brasileiro, um seminário dedicado ao conjunto de romances da escritora - o $1^{\circ}$ Seminário Leituras de Jane Austen no Século XXI, realizado na Universidade Federal do Amazonas com duração de três dias. Contou com a apresentação de diversos trabalhos, palestras sobre a formação do leitor do período em que as obras de Austen foram produzidas, sobre educação da mulher e suas restrições sociais, leitura comparativa com autores brasileiros e adaptação teatral de Mansfield Park (1814).

Recentemente, a BBC - emissora pública de rádio e televisão do Reino Unido, de alcance internacional - lançou um jogo para Facebook em que os usuários da rede social podem passear pelos romances da escritora. Há, ainda, canais no YouTube: The Lizzie Bennet Diaries (2015), em que uma jovem tagarela, versão "moderninha" de uma das personagens mais famosas de Jane Austen, assume o papel de narradora, conta suas peripécias e apresenta os demais personagens, sempre com a marcada ironia que os fãs dos romances de Jane Austen louvam reiteradamente; e Emma Approved (2015), em que uma garota interpreta Emma Woodhouse, protagonista do livro Emma (1815) em uma versão atualizada, na qual a personagem fala sobre sua vida, sobre moda e diversos assuntos, além de estar presente em outras redes sociais.

Enquanto isso, desde 2001 acontece anualmente em Bath (cidade para a qual Austen se mudou com a família aos 25 anos) o Jane Austen Festival, um evento com recitais, bailes, desfiles da moda da época e aulas de etiqueta. Os participantes do evento se vestem com trajes comuns para a época em que os romances de Austen foram escritos. Mas os eventos dedicados à autora não se limitam a seu país de origem, no Brooklyn, USA, desde 1979 há um encontro anual de fãs de Jane Austen, o Annual General Meeting (AGM), organizado pela JASNA, Jane Austen Society of North America. No Brasil, por sua vez, os fãs de Jane Austen também contam com uma sociedade organizada, a JASBRA, Jane Austen Sociedade do Brasil. Oficializada em 2009, é resultado da confluência de interesses em torno de um blog produzido por fãs.

Diante desses dados, é inevitável que nos ocupemos de pensar sobre o que justificaria esse fascínio pela inglesa que nem ao menos viveu o suficiente para presenciar o início dessa aclamação. Parece possível afirmar que, apesar de ter vivido e escrito há mais de duzentos anos, Austen e suas histórias continuam atuais porque sua forma de escrita 
e os temas de que trata têm características percebidas como pertinentes às inquietações do período que vivemos. Os temas abordados em suas obras, os questionamentos acerca do papel social da mulher e da instituição familiar possivelmente ainda estão presentes, mesmo com as mudanças históricas efetivadas.

E tais mudanças têm a ver, por exemplo, com a cultura da produção industrial que multiplica objetos portadores de discurso. Há um conjunto de objetos que recolocam a questão sobre o modo de difusão de uma obra literária: podemos mencionar as ecobags com a frase "Keep calm and Love Mr. Darcy", "I Love Mr. Darcy", ou camisetas com os mesmos dizeres, canecas com a foto do ator Colin Firth no papel de Mr. Darcy; ou cortadores de biscoitos com o perfil de um personagem, ou seja, com um perfil idealizado, baseado em algum dos diversos atores que deram vida cinematográfica ao personagem. Há, também, bonecos dos personagens das obras de Austen, CDs com coletâneas de músicas "do tempo de Jane Austen", ou as "Músicas favoritas de Jane Austen", chás, joias, bijuterias e esmaltes inspirados no período descrito por Jane Austen, entre vários outros objetos paraeditoriais.

A circulação dessa autoria Jane Austen atinge proporções tão grandes que há um termo para designar os "discípulos de Jane Austen": Janeite(s), cunhado pelo estudioso George Saintsbury em sua introdução de uma nova edição de Orgulho e Preconceito no ano de 1894. O termo foi criado com vistas a diferenciar fãs comuns de estudiosos, assim, o "janeitisto" denominava o entusiasmo masculino compartilhado entre editores, professores e literatos. No entanto, após a "canonização" das obras de Austen e sua aceitação no ambiente acadêmico, entre 1930 e 1940, o termo passa a abrigar tanto uma conotação positiva quanto uma conotação negativa, uma vez que a obra passa a ter ainda maior circulação. Ao mesmo tempo em que os fãs passam a se autodenominar "Janeites", na academia o termo era utilizado para denominar aqueles que apreciavam a obra de maneira errada, ou seja, com fanatismo, um tipo de cultura de fã em que os "discípulos" veneram a obra e a vida de Austen (Cf. LYNCH, 2005).

Esse processo, como outros acima relatados, mostra bem o quanto as mediações institucionais, entre elas as mais propriamente editoriais, condicionam a recepção das obras ao delimitar formas de ler: práticas de leitura e também objetos a serem lidos ou que remetam a leituras feitas - ou que se deseja fazer, ou que se emulam.

Há, ainda, um forte marcador contemporâneo dessa recepção apaixonada: muitos fãs "declaram seu amor" pela autora e pela obra fazendo tatuagens, isto é, eternizando sua relação com Austen na própria pele, registrando supostas caricaturas de personagens, excertos de suas obras ou sua assinatura. 
- Notas sobre paratopia criadora: o caso de Jane Austen para além de sua fortuna crítica

\section{Uma topografia da criação}

Decerto há mais que dizer sobre o caso Jane Austen que, todavia, mesmo nesta breve abordagem, permite que voltemos à questão de fundo que foi proposta: em termos discursivos, como abordar o literário? Essa questão, dada a tradição de estudos e também as práticas que predominam hoje nos ambientes de troca dos objetos editoriais em que o literário se materializa, nos remete inescapavelmente à problemática da autoria. Aqui, propusemo-nos a testar a produtividade de um modelo teórico que nos parece apontar para avanços na abordagem da criação como atividade discursiva distintiva, correlata de certas formas de recepção que a consagram, consagrando não necessariamente um nome de autor, como é o caso de Austen, mas sempre uma dinâmica entre as instâncias que só em rebatimentos recíprocos instituem esse lugar, cujo efeito é de "impossível lugar", posto que o literário supõe o mundo em que se produz e, ao mesmo tempo, a recusa desse mundo no estabelecimento de um outro, alhures e paradoxalmente presentificado.

Digamos, por ora, que nessa abordagem "não se trata de dizer o que as obras significam, mas em que condições o fato literário é possível, e os textos literários podem se abrir à interpretação" (MAINGUENEAU, 2006, p. 323). Interessa, dessa perspectiva, destrancar o literário de qualquer redoma histórica que o tenha feito soar debilitado ou restrito a um ou outro modo de viver: a perspectiva da paratopia criadora abre para um entendimento do movimento de tessitura desse lugar que é sempre um vir a ser, feito de instâncias que abrigam muitos a trabalhar pela construção de um um - e é justamente aí que pulsa a vitalidade dos textos, que são criados, produzidos, mediados, distribuídos, recebidos, etc., e só são textos quando há imbricação entre essas etapas.

\section{Referências}

AUSTEN, J. Orgulho e preconceito. Tradução de Roberto Leal Ferreira. São Paulo: Martin Claret, 2012a.

AUSTEN, J. Razão e sensibilidade. Tradução de Roberto Leal Ferreira. São Paulo: Martin Claret, 2012b.

AUSTEN, J. Persuasão. Tradução de Roberto Leal Ferreira. São Paulo: Martin Claret, 2012c.

BENTON, M.; GUTJAHR, P. How typography conveys and affects meaning, from the Bible to comic books. Amherst: University of Massachusetts Press, 2001.

CHARTIER, R. O que é um autor? Revisão de uma genealogia. Tradução de Luzmara Curcino Ferreira. São Carlos: EdUFSCar, 2012. 
CHIEREGATTI, A. Leituras da paratopia criadora de Jane Austen: uma oitocentista contemporânea. 2014. 92 f. Trabalho de Conclusão de Curso (Letras) - Centro de Ciências Humanas, Universidade Federal de São Carlos, São Carlos, 2014.

EMMA Approved. Disponível em: <http://www.youtube.com/user/EmmaApproved>. Acesso em: 10 nov. 2015.

LYNCH, D. Cult of Jane Austen. In: LYNCH, D. Jane Austen In Context. Ed. Janet Todd. Cambridge: Cambridge University Press, 2005.

MAINGUENEAU, D. Gênese dos discursos. Tradução de Sírio Possenti. 2. ed. São Paulo: Parábola, 2008.

MAINGUENEAU, D. Discurso literário. Tradução de Adail Sobral. São Paulo: Contexto, 2006.

NIETZSCHE, F. Genealogia da moral. Tradução, notas e prefácio de Paulo César de Souza. São Paulo: Companhia das Letras, 1998 [1887].

SALGADO, L. S. Ritos genéticos editoriais: autoria e textualização. Bragança Paulista: Margem da Palavra, 2016.

THE LIZZIE Bennet Diaries. Disponível em: <http://www.youtube.com/user/ LizzieBennet>. Acesso em: 10 nov. 2015.

WOODMANSEE, M.; JASZI, P. The construction of authorship - textual appropriation in law and literature. 3. ed. London: Duke University Press, 2006 [1994].

COMO CITAR ESTE ARTIGO: SALGADO, Luciana Salazar; CHIEREGATTI, Amanda Aparecida. Notas sobre paratopia criadora: o caso de Jane Austen para além de sua fortuna crítica. Revista do GEL, v. 15, n. 2, p. 117-131, 2018. Disponível em: https://revistadogel.gel.org.br/

DOI: http://dx.doi.org/10.21165/gel.v15i2.1500

Submetido em: 18/10/2017 | Aceito em: 05/07/2018 